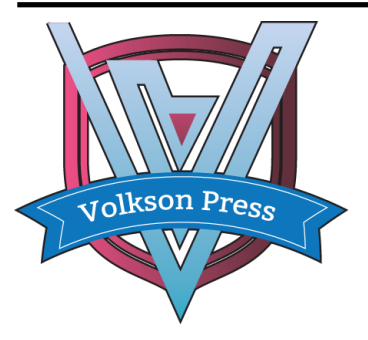

Contents List available at VOLKSON PRESS

New Materials and Intelligent Manufacturing (NMIM)

DOI : http://doi.org/10.26480/icnmim.01.2018.98.100

Journal Homepage: https://topicsonchemeng.org.my/

ISBN: 978-1-948012-12-6

\title{
DESIGN AND APPLICATION OF TIME-SHARING HEATING CONTROL SYSTEM BASED ON CONFIGURATION KING AND S7-200 SMART PLC
}

\author{
Qifeng*, Meng Ya-nan \\ Automation Department of Jilin Institute of Chemical Technology, \\ *Corresponding Author Email: 136961208@qq.com
}

This is an open access article distributed under the Creative Commons Attribution License, which permits unrestricted use, distribution, and reproduction in any medium, provided the original work is properly cited

\begin{tabular}{ll} 
ARTICLE DETAILS & ABSTRACT \\
\cline { 1 - 2 } Article History: & $\begin{array}{l}\text { As for the current heating situation of large heating companies, the types of heating users in the heating area are very } \\
\text { different. For example, residential areas require24 hours of uninterrupted heating. For office buildings and industrial } \\
\text { plants, etc., the desired heating target can be achieved through time-division heating. To achieve the purpose of saving } \\
\text { Received 26 June 2018 } \\
\begin{array}{l}\text { Accepted 2 July 2018 } \\
\text { Available online 1 August 2018 }\end{array}\end{array}$ \\
social and environmental protectiong purposes.
\end{tabular}

\section{KEYWORDS}

Time-sharing heating, Energy conservation, Environmental protection

\section{INTRODUCTION}

In the current heating system, heating control is generally carried out by adjusting the water supply temperature of the secondary network according to the outdoor temperature and by relying on the experience; due to the hysteresis of the temperature, when the outdoor temperature changes significantly, it is difficult to adjust the water temperature to an ideal value in a short time. In order to ensure the heating room temperature, so under normal circumstances the use of large flow, a small temperature difference operation, resulting in widespread energy waste, cannot achieve economic operation. The special groups of hot users mainly refer to school buildings, workshops, and garages. These hot users are characterized by very few people working or studying in the room at night or on holidays. However, the amount of heating has not changed, so there is a large space for energy saving, so time-sharing heating should be adopted.

\section{STATUS QUO OF EQUIPMENT}

(1). The regulating valve has been installed in the primary network of the equipment, which can be controlled by PID according to the setting value of the water supply temperature of the secondary network.

(2). The secondary net circulating pump is controlled by the inverter, and the frequency can be set manually.

(3). The system is equipped with Beijing Subcontrol Configuration king PC software.

\section{TIME-SHARING HEATING CONTROL SYSTEM}

The time-sharing heating control system is based on the outdoor temperature curve, and for special heating users, the system automatically controls the temperature of the secondary network water supply through the PLC control program according to the weather forecast system during the unoccupied time period, and finally, the indoor temperature can be reduced properly, energy can be saved, and energy waste can be avoided.
Configuration king and Siemens S7-200 SMART PLC. The on-site temperature, pressure and flow signals have been collected into the PLC and connected with the Configuration king via the TCP/IP protocol.

\subsection{Domination principle}

A system time collector is added to a heating system of a special user of the original system, and the system time and the timing time are compared. The system time is compared with the regular time. If the system time exceeds the time low limit and is less than the time limit, the circulating pump will work according to the current frequency set value, if the system If the time exceeds the time limit, the system automatically enters the next time period, and the circulating pump will also work according to the prefabrication frequency in the next time period. The system will automatically adjust the opening degree of the electric control valve according to the outdoor temperature curve of the weather forecast for the next 24 hours, set the secondary network water supply temperature and control the time curve of the circulation pump running and stopping, and finally can automatically achieve intermittent heating, reducing the Human input and improve system reliability. The control center can monitor the heating condition of each sub-control point in real time and adjust the operation of heating source boiler according to the change of heating energy consumption of each time-sharing / partitioning control point in time.

\subsection{Programming}

\subsubsection{Design of Meteorological Management function}

(1) Configure meteorological management module General configuration software, KingSCADA/KingHistorion+ weather management module needs to be configured to connect the host computer to the Internet to realize real-time acquisition and prediction of local meteorology. The results are shown in Figure 1.

\subsection{System composition}




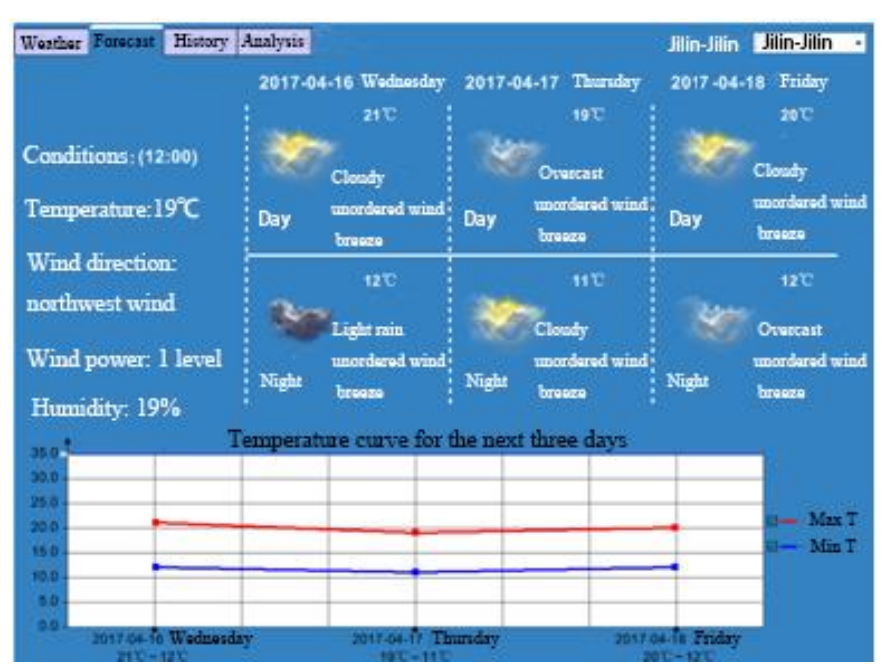

Figure 1: Weather Forecast

(2) Operation interface design

Use Configuration King to establish a time-division upper computer operation interface, add function controls, link variables to achieve the set of time and temperature points, as shown in Figure 2:

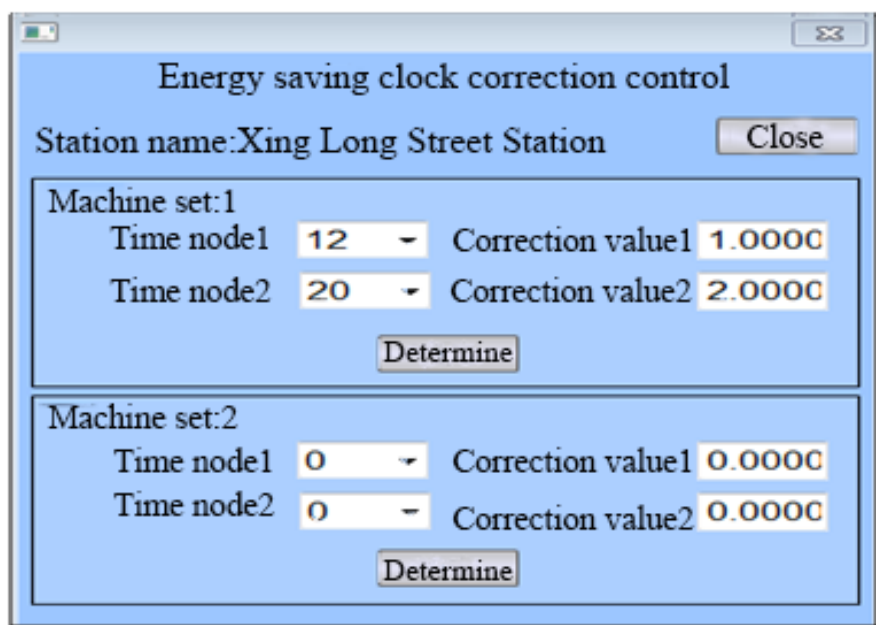

Figure 2: Operating Interface

Through the operation interface, input different time period corresponde nce.

\subsubsection{PLC programming}

The existing S7-200 SMART PLC is programmed to synchronize the PLC clock with the standard clock, and automatically control the start, stop, and set frequency of the inverter according to the clock according to the settings of the host computer, or it can also automatically set the temperature of the two-network water supply according to the outdoor temperature curve ${ }^{[2]}$.

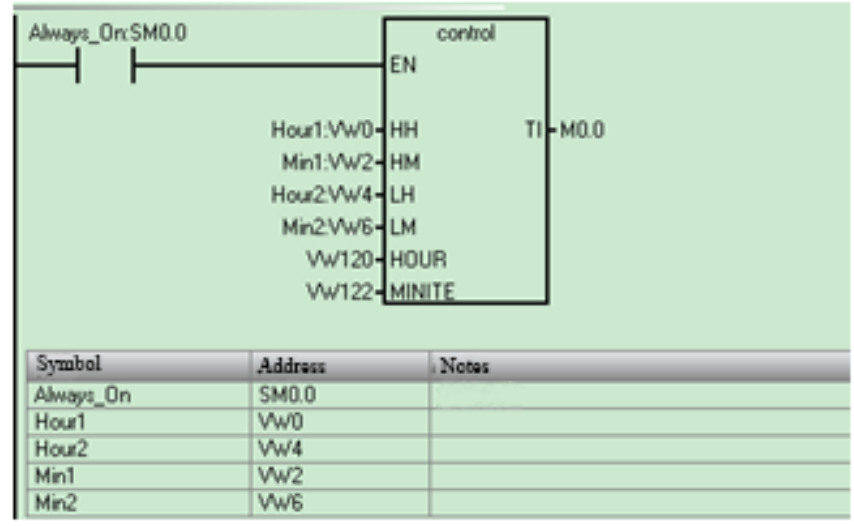

Figure 3: Start, stop, control of the inverter

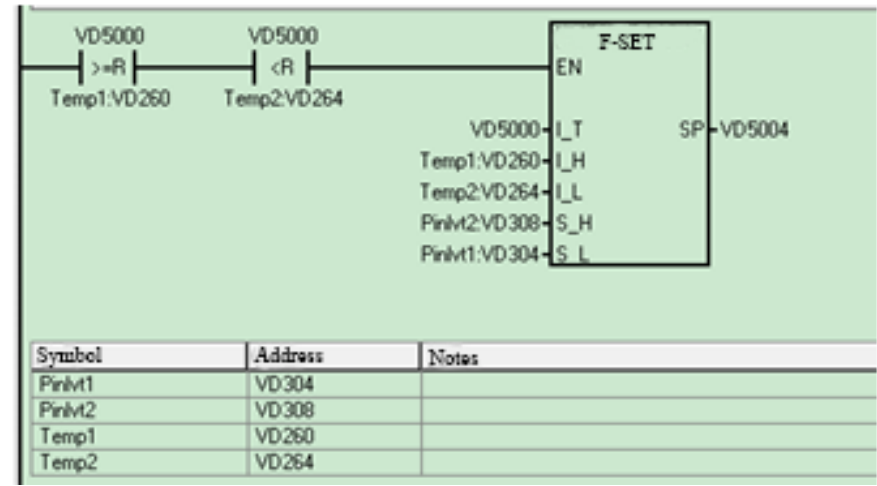

Figure 4: Frequency setting of frequency converter

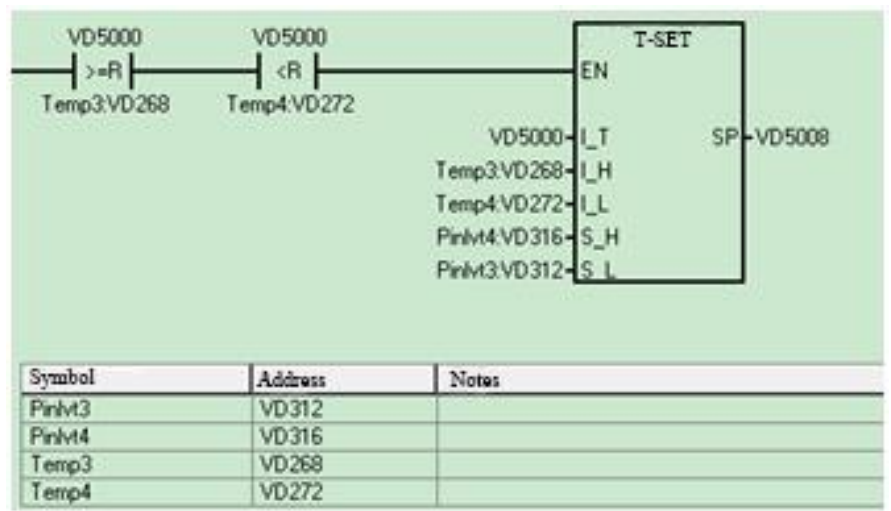

Figure 5: Secondary network temperature setting

\section{FIELD APPLICATION AND EFFECT}

Take a primary school teaching building and a community garage as an example. See Table 1. According to the average proportion of all types of buildings in the residential area, the design heat index of the central heating in the residential area is $60 \mathrm{~W} \mathrm{~m} \mathrm{~m}^{2}$, the Heating heat consumption index is $31.5 \mathrm{~W} \mathrm{~m}^{2}[1]$.

Table 1: Heating Information

\begin{tabular}{|c|c|c|c|c|c|c|}
\hline $\begin{array}{l}\text { Name of } \\
\text { Buildings }\end{array}$ & $\begin{array}{l}\text { Building } \\
\text { Area }\end{array}$ & Heating Period & Target Temperature $\left({ }^{\circ} \mathrm{C}\right.$ & $\begin{array}{l}\text { Heating } \\
\text { Index }\end{array}$ & $\begin{array}{l}\text { Heating } \\
\text { (days) }\end{array}$ & Period \\
\hline \multicolumn{7}{|l|}{$\begin{array}{l}\text { Teaching } \\
\text { building }\end{array}$} \\
\hline \multicolumn{7}{|l|}{ Garage } \\
\hline & $1115 \mathrm{~m}^{2}$ & $8: 00-3: 00$ & 10 & $50 \mathrm{~W}$ & 165 & \\
\hline
\end{tabular}


The energy consumption of conventional heating and time-sharing / partitioning heating is compared Supply heating can see Table 2.

Table 2: Comparison of Energy Consumption Before and After Timesharing and partitioning heating

\begin{tabular}{|c|c|c|c|c|c|c|c|c|c|}
\hline \multirow[t]{2}{*}{ Place } & \multirow{2}{*}{$\begin{array}{l}\text { Current Heating } \\
\text { Mode Energy } \\
\text { Consumption / } \\
\text { (GJ.a-1) }\end{array}$} & \multicolumn{4}{|c|}{$\begin{array}{l}\text { Time-Sharing Heating Energy consumption } \\
\text { (GJ.a-1) }\end{array}$} & \multirow{2}{*}{$\begin{array}{c}\text { Save } \\
\text { Energy } \\
\text { Consumpt } \\
\text { io-n (GJ.a- } \\
\text { 1) }\end{array}$} & \multirow{2}{*}{$\begin{array}{l}\text { Coal } \\
\text { Savin } \\
\text { g( } \\
\text { t.a }^{-1} \\
\text { ) }\end{array}$} & \multirow{2}{*}{$\begin{array}{l}\text { Material } \\
\text { Saving } \\
\text { yuan.a-1) }\end{array}$} & \multirow{2}{*}{$\begin{array}{c}\text { One- } \\
\text { time } \\
\text { Investm } \\
\text { en-t } \\
\text { (yuan) }\end{array}$} \\
\hline & & $\begin{array}{l}\text { Norma } \\
1 \\
\text { Heatin } \\
\mathrm{g}\end{array}$ & $\begin{array}{l}\text { Abnorm } \\
\text { al } \\
\text { Heating }\end{array}$ & $\begin{array}{c}\text { Winter } \\
\text { Vacati } \\
\text { on }\end{array}$ & $\begin{array}{l}\text { Sum- } \\
\text { ation }\end{array}$ & & & & \\
\hline $\begin{array}{l}\text { Teaching } \\
\text { building }\end{array}$ & 8461 & 4275 & 1804 & 879 & 6958 & 1503 & 79 & 55300 & 28723 \\
\hline Garage & 702 & 147 & 396 & - & 543 & 159 & 8.7 & 6090 & 7329 \\
\hline
\end{tabular}

By contrast, the time-sharing heating method can be implemented to save energy consumption, and the installation cost and various costs of the renovation input can be fully realized in a heating period. Moreover, the current heating users, such as teaching buildings, office buildings, and garages, account for a large proportion of all hot users, so the market prospects are relatively broad.

\section{CONCLUSION}

The time-sharing / partitioning heating method can get large economic benefits through a small capital investment; effectively improve the utilization ratio of equipment, which reduce coal consumption and carbon dioxide emissions. It is a scientific and reasonable heating method. For some office buildings, factories and garages as well as the heating area of schools, which occupy a large proportion, the use of time-sharing / partitioning heating has broad prospects and is conducive to the stable and sustainable development of heating companies. If time-sharing heating is adopted, the energy saving, and emission reduction and environmental protection will be greatly improved, which will bring great economic benefits and social value to enterprises.

\section{REFERENCES}

[1] Guohui, F., Xinhong, L., Songkan, Z., Shaowen, S. 2003. Analysis on Heat Indexof heating Design of Energy-saving Building in Residential a rea [J]. Energy conservation, (04), 36-39.

[2] Jian, H. 2008. Siemens S7-300/400 PLC engineering application [M]. Beijing : Beijing University of Aeronautics and Astronautics Press.

\section{ABOUT THE AUTHORS}

Qi feng, male, master, study in automation at Jilin chemical institute, mainlv engaged in the research of industrial automation 